\title{
Bulk Power Generator Produces More Power Per Tower
}

\section{From its design and manufacturing to its delivery and installation, the Amonix 7700 is a fully conceived and deployable CPV technology with the potential to change the energy market.}

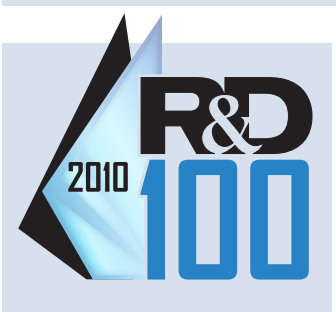

Concentrating photovoltaic (CPV) systems are well-matched to utility-scale solar energy projects, especially in sunny and dry climates. A stellar example of this is the Amonix 7700 Solar Power Generator, a high-power, small-footprint system that is optimized for utility applications.

The 7700 is a 53-kilowatt (kW) high-concentration photovoltaic (PV) power generator based on the MegaModule, a turnkey unit pairing a durable Fresnel lens with high-efficiency multijunction cells. With its low-cost, high-efficiency design, the Amonix 7700 concentrates the energy of the sun to generate bulk power-"more power per tower"- than any of its competitors. The 7700's highly efficient solar cells, tried-and-true concentrator Fresnel lenses, and "smart" controller and tracker make it the first terrestrial PV system capable of converting one-fourth of the sun's energy into usable electricity - $\mathrm{a} 40 \%$ gain on conventional fixed solar panels.

Its utility-scale size reflects its desired impact on the energy grid: reducing costs and land use. The Amonix 7700 is a game-changer in propelling solar electricity to grid parity with fossil fuels.

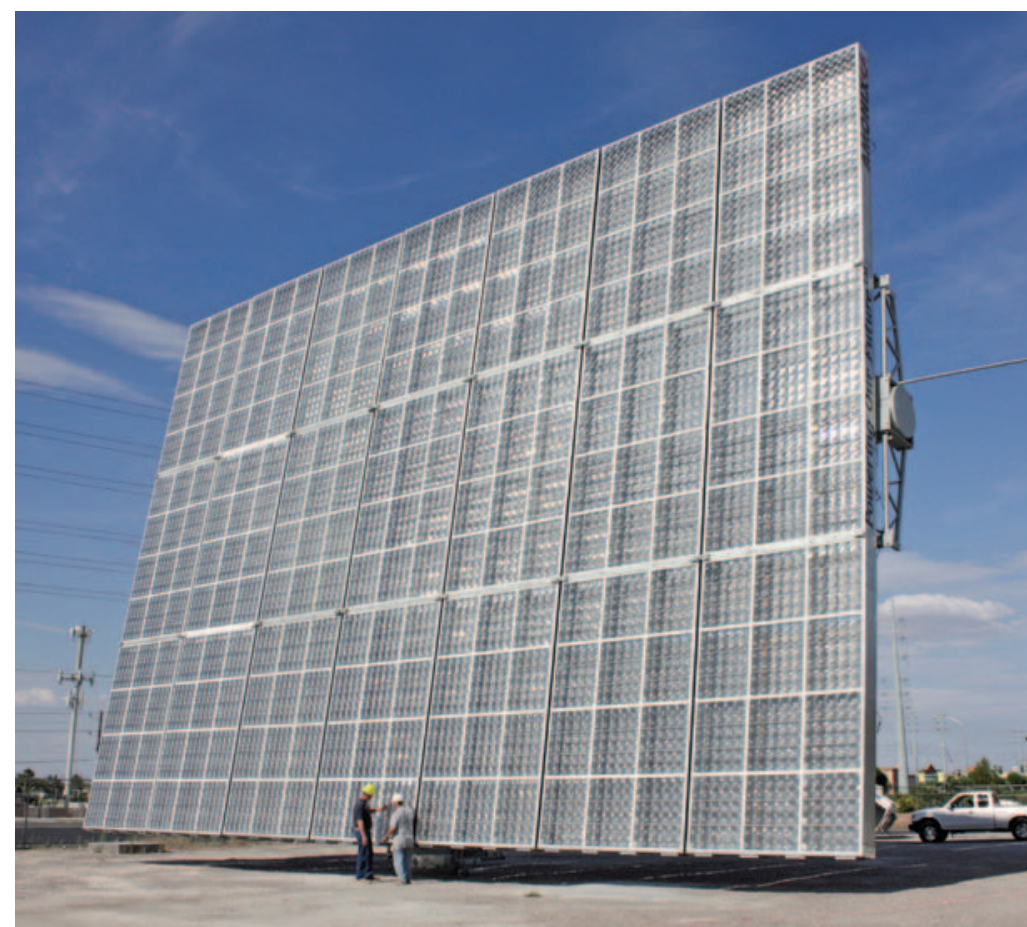

The Amonix $\mathbf{7 7 0 0}$ Solar Power Generator produces more electricity on less land than any other commercially available PV system. Credit: Amonix

\section{Developing the Next Generation of Solar Technology}

Since the company's inception in the early 1990s, Amonix has designed, fabricated, and field-tested seven design generations of CPV technologies. Amonix partnered with the U.S. Department of Energy's (DOE's) National Renewable Energy Laboratory (NREL) to further increase the efficiency of its existing solar device after achieving some success using crystalline-silicon PV cells.

NREL's 1991 invention of the multijunction PV cell - a durable and reliable means of obtaining high PV conversion efficiency - was applied in the redevelopment of the Amonix flagship CPV system. This was accomplished in partnership with NREL through its High-Performance PV Project funded by the DOE Solar Energy Technologies Program. Other DOE-funded support came from the Small Business Innovation Research and Technology Pathway Partnership programs. DOE's Sandia National Laboratories and Brookhaven National Laboratory also facilitated the scale-up of this project.

After substituting a high-efficiency multijunction PV cell with about $41.6 \%$ record efficiency for the previously used silicon cell with about $27.6 \%$ efficiency, engineers developed the Amonix seventhgeneration 7700 . It demonstrates a $50 \%$ increase in solar power output over that of its previous generations.

This surge in power output clears the path to meeting the world's demand for terawatts of carbon-free electricity at a low cost.

\section{Designed to Deliver}

The Amonix 7700 modular design is key to the system's low cost and high efficiency. Each 7700 has seven MegaModules, each of which uses 1,080 highefficiency multijunction PV cells. Approximately $1 \mathrm{~cm}^{2}$ in individual area, these cells are exposed to focused sunlight equivalent to 500 suns using the Amonix Fresnel lens. Made of an inexpensive acrylic material, the lens uses refractive optics to concentrate the sun's irradiance onto a solar cell. The cell then converts the sun's power into electrical power.

The Amonix patented hydraulic-drive, dual-axis "smart" tracker keeps the sun's rays focused directly onto the concentration lenses and into the PV cells. 


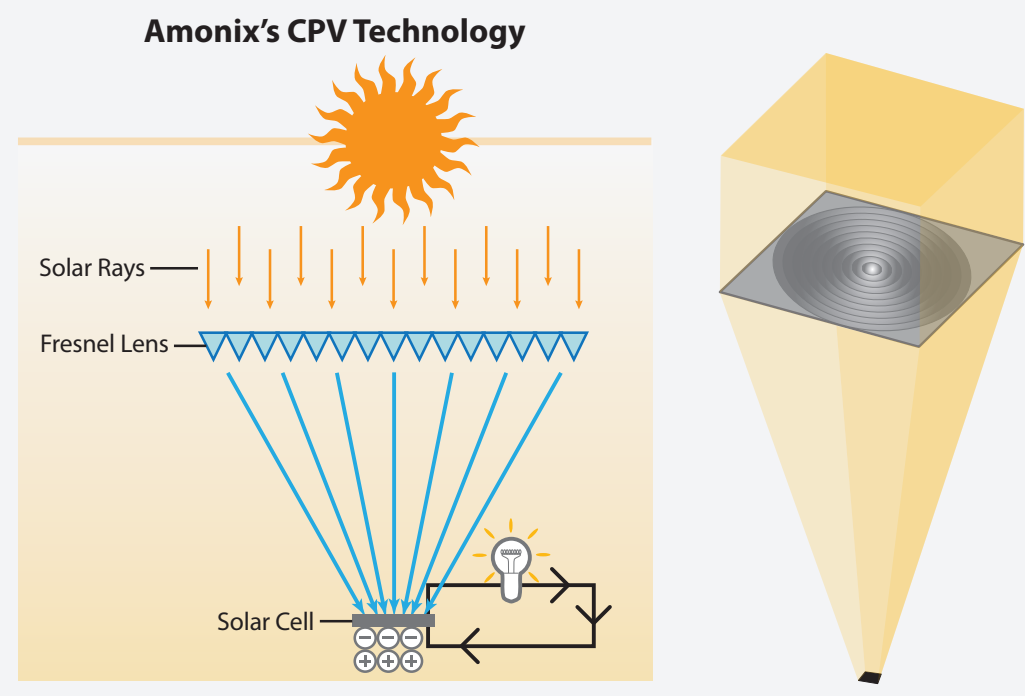

The Amonix Fresnel lens concentrates the sun's rays onto ultrahigh-efficiency solar cells.

An inverter system takes direct current (DC) from the solar generator and converts it to alternating current (AC) and then interconnects with the AC utility grid.

Introduced to the solar marketplace in 2009, the Amonix 7700 has proven to be a major advance, achieving an industry-leading sunlight-to-electricity conversion efficiency. It converts $28.9 \%$ of solar energy into $67 \mathrm{~kW}$ of DC electricity as measured by Sandia National Laboratories.

\section{A Total-Systems Approach: Competitive Advantages at Every Level}

Leveraging more than 15 years of CPV field testing by Amonix - the recognized industry leader - the 7700's advantages as recognized by a 2010 R\&D 100 award include the optimization of:

- Efficiency and Performance: With a verified efficiency of about $25 \%$ (AC), the 7700 produces more energy per acre than any other PV system, which maximizes return on investment.

- Size and Module Capacity: At 53 kW (AC), the Amonix 7700 boasts the largest size and highest capacity on the market. Its size is optimal for both transporting on a standard flatbed truck and for quick and easy installation in the field.

- Installation, Operation, and Maintenance: Factory assembly of the device's primary component, the MegaModule, allows the reduction of installation time from months to days. Operating and maintaining the 7700 is streamlined based on the design modularity. The ability to replace individual components also presents the option to upgrade or "repower" the system to extend the plant life to 50 years.

- Cost and Manufacturing: Headquartered in Seal Beach, California, Amonix uses a turnkey manufacturing system that incorporates cost savings at each step of the manufacturing-toinstallation pipeline. Using state-of-the-art robotics and a capital-efficient (one-half to one-third the cost of competing technologies) process enables distributed manufacturing. Integration of the lens, mounting structure, and solar cell into a single unit eliminates more than $75 \%$ of the parts and costs associated with other concentrator designs. Levelized cost of energy for the 7700 will be $25 \%$ lower than competitors for large-scale projects of $100 \mathrm{MW}$ and larger.

\section{Changing the Energy Playing Field: The Future of the Amonix 7700}

As its main application is for producing utility-scale PV power, the Amonix 7700 is an excellent fit for the solar market, which is projected to be a $\$ 100$ billion industry by 2013 , with utility installations expected to constitute a $75 \%$ market share.

Amonix CPV technology is expected to enjoy steady upward efficiency gains in the next 3-5 years, with strong headroom remaining before CPV begins to approach cell-efficiency limits. This will be achieved via new cell and gridline designs, a new antireflective coating, and increased concentration from a reducedfocal-length lens. Amonix has received a multimilliondollar cash infusion from a venture capital company for continued commercial development of the 7700 .

\section{For More Information}

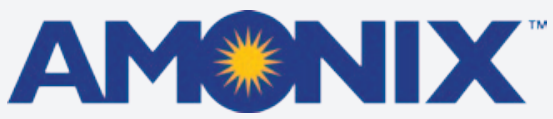

Robert McConnell

562-200-7741

bob@amonix.com

National Renewable Energy Laboratory Martha Symko-Davies

303-384-6528

martha.symko.davies@nrel.gov 